\title{
Analysis of increased nuchal translucency: Chorionic villi sampling and second-trimester level II sonography
}

\author{
Ji Eun Park', Ji Kwon Park,2, In Ae Cho', Jong Chul Baek, Min Young Kang ${ }^{1}$, Jae Ik Lee', Jeong Kyu Shin ${ }^{1,2}$, Won Jun Choi ${ }^{1,2}$, \\ Soon Ae Lee ${ }^{1,2}$, Jong Hak Lee ${ }^{1,2}$, and Won Young Paik Pik $^{1,2}$ \\ 'Department of Obstetrics and Gynecology, Institute of Health Sciences, School of Medicine, Gyeongsang National University, Jinju, Korea
}

Purpose: To assess the outcomes of increased fetal nuchal translucency (NT), to aid in prenatal counseling and management in our practice.

Materials and Methods: We retrospectively reviewed the medical records of patients who underwent first trimester fetal karyotyping using chorionic villi sampling (CVS) and second trimester level II sonography for a fetal NT thickness $\geq 3.0 \mathrm{~mm}$ between 11 weeks and 13 weeks 6 days' gestation, at Gyeongsang National University Hospital. Pediatric medical records and a telephone interview were used to follow-up live-born children. Exclusion criteria included incomplete data and CVS for other indications.

Results: Seventy cases met the inclusion criteria (median NT thickness, $4.7 \mathrm{~mm}$; range, 3.0-16.1 mm). Twenty-nine cases (41.4\%) were aneuploid. The prevalence of chromosomal defects increased with NT thickness: NT 3.0-3.4 mm, 16.7\%; NT 3.5-4.4 mm, 27.3\%; NT 4.5-5.4 mm, 66.7\%; NT 5.5-6.4 mm, 37.5\%; NT $\geq 6.5$ mm, 62.5\%. The most common karyotype abnormality was trisomy $18(n=12)$, followed by trisomy $21(n=9)$. In chromosomally normal fetuses $(n=41)$, fetal death occurred in 2 cases $(4.9 \%)$, and structural malformations were found in 11 cases $(26.8 \%)$. In chromosomally and anatomically normal fetuses $(\mathrm{n}=28)$, one child had neurodevelopmental delay $(3.6 \%)$. Twenty-eight infants who had a prenatal increased NT were alive and well at follow-up (40\%).

Conclusion: Outcomes of increased fetal NT might help inform prenatal counseling and management. The high prevalence of chromosomal defects associated with increased fetal NT implies that CVS should be performed in the first trimester, particularly considering the stress associated with an uncertain diagnosis.

Key words: Increased fetal nuchal translucency, Chorionic villi sampling, Chromosomal defects, Structural malformations.

\section{Introduction}

The association between the collection of fluid in the fetal neck and Down's syndrome was first discovered in 1990 [1]. Thereafter, with the refinement of ultrasound imaging, this fluid retention has been named fetal nuchal translucency (NT); the risk of aneuploidy is high when fetal NT is increased by more than $3 \mathrm{~mm}$ [2]. It has become clear that measurement of NT thickness is the most representative and useful screening test for aneuploidy during the first trimester [3]. There is emerging data that indicates increased NT thickness is associated with a wide

Received: 27 October 2014, Revised: 26 November 2014, Accepted: 2 December 2014, Published: 31 December 2014

${ }^{*}$ Corresponding author: Ji Kwon Park, M.D., Ph.D.

Department of Obstetrics and Gynecology, School of Medicine, Gyeongsang National University, 15 Jinju-daero 816beon-gil, Jinju 660-751, Korea.

Tel: +82-55-750-8152, Fax: +82-55-759-1118, E-mail: obgypjk@gnu.ac.kr

Conflict of interest: We declare that we do not have any conflicts of interests.

(c) This is an open-access article distributed under the terms of the Creative Commons Attribution Non-Commercial License (http://creativecommons.org/licenses/by-nc/3.0/) which permits unrestricted non-commercial use, distribution, and reproduction in any medium, provided the original work is properly cited.

(c) Copyright 2014 by the Korean Society of Medical Genetics 
spectrum of structural anomalies of the heart and other organs, as well as genetic syndromes, and increased risk of aneuploidy. The risk of each of these anomalies is proportionally related to the degree of NT thickening [4-7]. Furthermore, fetuses with increased NT thickness have an increased risk of an adverse pregnancy outcome, such as fetal loss and developmental delay $[6,8]$.

The advantage of chorionic villi sampling (CVS) is that the results are available early in pregnancy, which lessens parental anxiety when they are normal, and allows earlier and safer methods of pregnancy termination when they are abnormal. When CVS is performed by an experienced operator after 10 weeks of gestation, the procedure-related fetal loss rate is comparable to that of amniocentesis [9]. However, the loss rate is affected by the indication for CVS. Fetuses with increased NT thickness have a higher likelihood of death because of background spontaneous losses; that is, deaths that would have occurred between the first and second trimester in the absence of any procedure.

The aim of the present study was to assess the outcomes of both increased fetal NT thickness and CVS-related fetal loss. Our results will help inform prenatal counseling and the management of pregnancies in which an increased fetal NT thickness has been observed.

\section{Materials and Methods}

This was a retrospective study of patients who had undergone first trimester fetal karyotyping using CVS, following the finding of an increased fetal NT thickness $(\geq 3.0 \mathrm{~mm})$ at 11 weeks and 13 weeks 6 days of gestation. In cases of euploidy, second-trimester level II sonography was also performed. All investigations were undertaken at the Department of Obstetrics and Gynecology, Gyeongsang National University Hospital (Jinju, Korea) between January 1, 2007 and April 30, 2014. Additionally, the followup of a live-born child was conducted using pediatric medical records and a telephone interview. Exclusion criteria for the present study included incomplete data and CVS for other indications.

Detailed transabdominal and transvaginal ultrasound examinations were performed prior to CVS to confirm the gestational age, assess the fetal anatomy, and assess the placental location. Fetal NT thickness was measured using transabdominal or transvaginal sonography (Accuvix XQ,
Accuvix A30, or WS80A; Samsung Medison, Seoul, Korea). Measurements were made at an appropriate mid-sagital section of the fetus and a neutral position of the fetal head, using a magnification such that the fetus occupied at least 75\% of the image. One expert examiner (Park JK) performed at least 3 measurements in each case, the largest of which was recorded. An increase was defined as an increase in NT thickness $\geq 3 \mathrm{~mm}$ (Fig. 1).

For an NT of $\geq 3 \mathrm{~mm}$, CVS was carried out for fetal karyotyping by an experienced operator (Park JK). All patients were informed of the risks and benefits of CVS, and provided written informed consent. We performed CVS using a transcervical or transabdominal approach; the choice of approach depended on the placental location and uterine condition. The transcervical approach was carried out using an echogenic catheter (Angiomed, Karlsruhe, Germany) (Fig. 2A), and the transabdominal approach was carried out using a doubleneedle technique (Fig. 2B) under ultrasound guidance.

After the karyotyping results were obtained, euploid fetuses were investigated for the presence of structural abnormalities using level II sonography in the second trimester. Follow-up of all live-born children with no chromosomal or structural defects, to least one year of age, was performed using the pediatric medical records and a telephone interview; child development was assessed by the child's pediatrician using the Denver Developmental Screening Test.

\section{Results}

During the study period, 93 pregnant women had fetuses

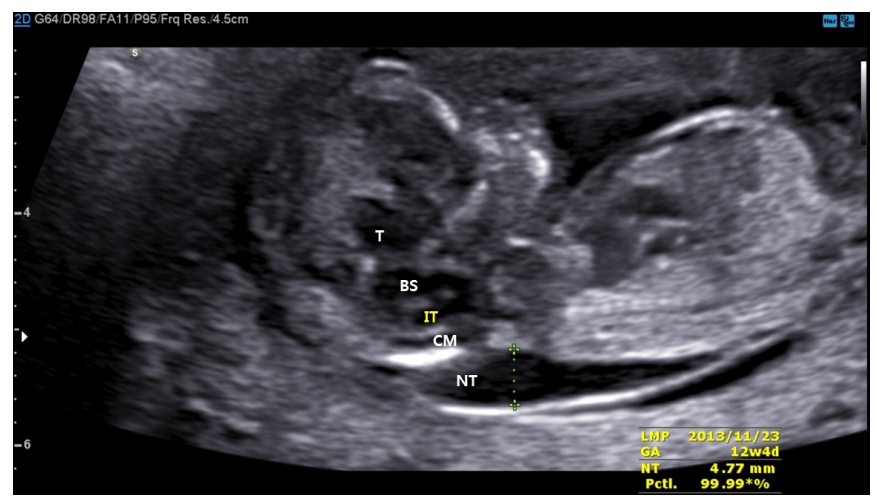

Fig. 1. Increased fetal nuchal translucency (NT) thickness and absent nasal bone at 12 weeks 4 days of gestation. T, thalamus; BS, brain stem; IT, intracranial translucency; CM, cisterna magna. 

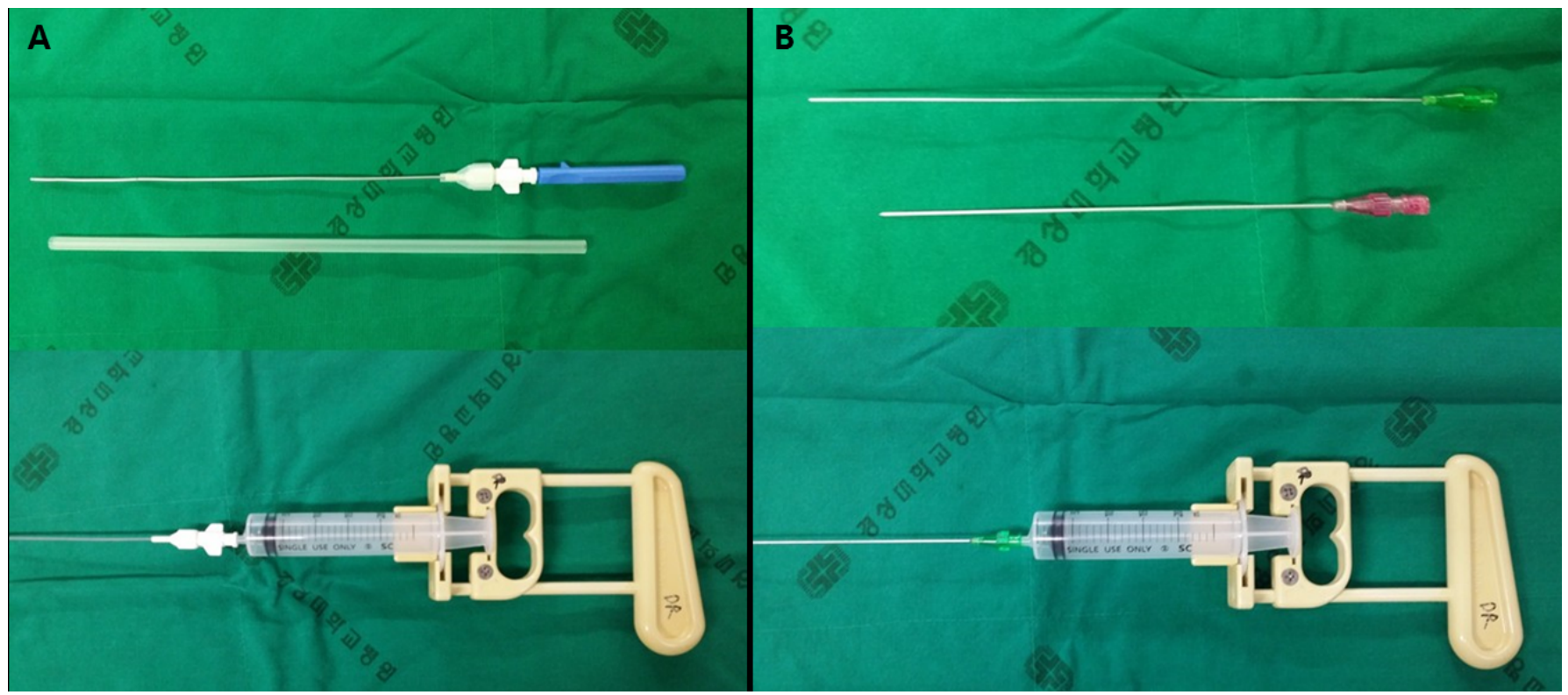

Fig. 2. (A) Transcervical chorionic villi sampling carried out using an echogenic catheter. (B) Transabdominal chorionic villi sampling carried out using an 18- and a 21-gauge double needle.

Table 1. Relationship between nuchal translucency and the prevalence of chromosomal defects, and adverse outcomes in euploid fetuses

\begin{tabular}{|c|c|c|c|c|}
\hline \multirow{2}{*}{$\begin{array}{l}\text { Nuchal translucency } \\
\qquad(\mathrm{mm})\end{array}$} & \multirow{2}{*}{ Chromosomal defects } & \multicolumn{3}{|c|}{ Euploid } \\
\hline & & Fetal death & Major structural abnormalities & Alive and well $^{b}$ \\
\hline $3.0-3.4(n=12)$ & $2(16.7)$ & 0 & $1(8.3)$ & $9(75)$ \\
\hline $3.5-4.4(n=22)$ & $6(27.3)$ & $1(4.5)$ & $2(9.1)$ & $13(59.1)$ \\
\hline $4.5-5.4(n=12)$ & $8(66.7)$ & 0 & $1(8.3)$ & $3(25.0)$ \\
\hline $5.5-6.4(n=8)$ & $3(37.5)$ & 0 & $3(37.5)$ & $2(25.0)^{c}$ \\
\hline$\geq 6.5(\mathrm{n}=16)$ & $10(62.5)$ & $1(6.3)$ & $4(25.0)$ & $1(6.3)$ \\
\hline Total $(n=70)$ & $29(41.4)$ & $2(2.9)$ & $11(15.7)$ & $28(40.0)$ \\
\hline
\end{tabular}

Values are presented as number (\%).

The median value of NT was $4.7 \mathrm{~mm}$ (range, 3.0-16.1 mm).

"We defined "alive and well" as the prevalence of delivery of a healthy baby with no major structural abnormality. Children of at least one year of age were developmentally assessed by a pediatrician using the Denver Developmental Screening Test.

${ }^{\circ}$ One case had a developmental delay.

with an increased NT $\geq 3 \mathrm{~mm}$. Thirteen pregnant women who had undergone amniocentesis instead of CVS were excluded due to inadequate sampling $(n=11)$ or chorionic villus culture failure $(n=2)$. In the remaining 80 pregnant women carrying fetuses with an increased NT thickness, cytogenetic analysis with CVS was performed at 11-14 weeks of gestation. Of these women, 10 were lost to follow-up, resulting in a final study population of 70 women. The median NT thickness was $4.7 \mathrm{~mm}$ (range, 3.0-16.1 $\mathrm{mm})$.

The relationship between NT thickness and the prevalence of chromosomal defects, and fetal death or major structural abnormalities in euploid fetuses, are summarized in Table 1. Among the 70 fetuses, 29 (41.4\%) exhibited aneuploidy. The prevalence of chromosomal defects increased with NT thickness: $16.7 \%(n=2)$ for an NT of 3.0-3.4 mm ( $n=12) ; 27.3 \%(n=6)$ for an NT of 3.5-4.4 mm ( $n=22) ; 66.7 \%(n=8)$ for an NT of 4.5-5.4 $\mathrm{mm}(\mathrm{n}=12) ; 37.5 \%(\mathrm{n}=3)$ for an NT of 5.5-6.4 mm (n=8); and $62.5 \%(n=10)$ for an NT of $\geq 6.5 \mathrm{~mm}(n=16)$.

Two of the 41 chromosomally normal fetuses died (2.9\%). In one case, CVS was performed in a fetus with an NT of $3.6 \mathrm{~mm}$ at 11 weeks 6 days of gestation; fetal death occurred at 17 weeks 1 days of gestation. In the other case, CVS was performed in a fetus with an NT of $10 \mathrm{~mm}$ at 11 weeks 6 days of gestation; fetal death occurred at 13 weeks 6 days of gestation. Among the remaining euploid fetuses $(n=39)$, structural malformations were diagnosed in 11 (15.7\%). These consisted of ventricular 
Table 2. Adverse outcomes in euploid fetuses

\begin{tabular}{|c|c|c|c|c|c|}
\hline Varaiable & $\mathrm{CRL}(\mathrm{cm})$ & $\mathrm{NT}(\mathrm{mm})$ & Second-trimester level II sonography finding & $\begin{array}{c}\text { Fetal death } \\
\text { (gestational age) }\end{array}$ & Pregnancy outcome \\
\hline \multicolumn{6}{|l|}{ Miscarriage } \\
\hline 1 & 5.21 & 3.6 & - & 17 weeks 1 day & TOP (17 weeks 1 day) \\
\hline 2 & 5.00 & 10.0 & - & 13 weeks 6 days & TOP (13 weeks 6 days) \\
\hline Median & 5.11 & 6.8 & & & \\
\hline \multicolumn{6}{|c|}{ Major structural abnormalities } \\
\hline 1 & 6.47 & 3.0 & VSD, ASD & & NFSD \\
\hline 2 & 4.98 & 3.5 & TOF & & CS \\
\hline 3 & 8.53 & 4.3 & $\mathrm{COA}$ & & NFSD \\
\hline 4 & 6.67 & 5.3 & AVSD, DORV & & CS \\
\hline 5 & 6.44 & 6.0 & Encephalocele & & TOP at local \\
\hline 6 & 6.29 & 6.0 & Left-sided CDH & & CS \\
\hline 7 & 3.94 & 6.3 & Chylothorax & & CS \\
\hline 8 & 4.66 & 7.0 & AVSD, HLHS, IAA & & TOP at local \\
\hline 9 & 4.12 & 9.4 & Phocomelia & & TOP at local \\
\hline 10 & 6.61 & 11.0 & Achondrogenesis & & TOP (18 weeks 6 days) \\
\hline 11 & 7.03 & 8.1 & AVSD & & TOP at local \\
\hline Median & 5.98 & 6.4 & & & \\
\hline
\end{tabular}

CRL, crown-rump length; NT, nuchal translucency; VSD, ventricular septal defect; ASD, atrial septal defect; TOF, tetralogy of Fallot; CoA, coarctation of the aorta; AVSD, atrioventricular septal defect; DORV, double-outlet right ventricle, CDH, congenital diaphragmatic hernia; HLHS, hypoplastic left heart syndrome; IAA, interrupted aortic arch; TOP, termination of pregnancy; NFSD, normal full-term spontaneous delivery; CS, cesarean section.

septal defect, atrial septal defect, atrioventricular septal defect, tetralogy of Fallot, coarctation of the aorta, interruption of the aortic arch, double-outlet right ventricle, hypoplastic leftheart syndrome, encephalocele, congenital diaphragmatic hernia, achondrogenesis, and phocomelia. The outcomes for chromosomally normal fetuses $(n=41)$ are summarized in Table 2.

The probability of live birth, without either a chromosomal defect or a major structural defect, was $40 \%(n=28)$. Of the normal fetuses $(n=28)$, one child had a neurodevelopmental delay, particularly affecting the acquisition of gross motor skills.

The pregnancy outcomes for chromosomally abnormal fetuses ( $n=29)$ are summarized in Table 3. Trisomy $18(n=12)$ was the most commonly detected karyotypic abnormality, followed by trisomy $21(\mathrm{n}=9)$. The median NT thickness was $5.5 \mathrm{~mm}$ (3.1-16.1 mm) in fetuses with trisomy 18 , and $5.3 \mathrm{~mm}(3.8-7.6$ $\mathrm{mm}$ ) in fetuses with trisomy 21. Of the aneuploid fetuses, first trimester or early second trimester ultrasonography detected other anomalies in 14 fetuses: absent nasal bone $(n=2)$, tricuspid regurgitation $(n=1)$, fetal hydrops $(n=6)$, ventricular septal defect $(n=5)$, atrioventricular septal defect $(n=2)$, double-outlet right ventricle $(n=1)$, and omphalocele $(n=2)$. All pregnancies with aneuploid fetuses were terminated at our hospital $(n=16)$ or at local clinics $(n=13)$.

\section{Discussion}

During the first trimester, fetal NT thickness is an important indicator that can be used to screen for chromosomal defects, and to predict the prognosis of pregnancy with normal chromosomes. The underlying pathophysiology of increased NT thickness is not yet fully understood, but several hypotheses have been proposed $[7,10]$. Possible causes of increased NT thickness include cardiac dysfunction, in association with abnormalities of the heart and great arteries; the presence of venous congestion in the head and neck; an altered composition of the extracellular matrix; and developmental delay of the lymphatic system [6,10-13].

Many cut-offs for increased NT thickness have been used [6]. Although there is ongoing debate concerning the cutoffs for increased NT thickness, there is a consensus that NT thickness above the 95 th centile $(3 \mathrm{~mm}$ ) or 99 th centile (3.5 $\mathrm{mm}$ ) is a definite increase [2,7]. In the present study, we used a cut-off of $3.0 \mathrm{~mm}$ for increased NT thickness. The prevalence of chromosomal defects with an NT of 3.0-3.4 mm $(n=12)$ was $16.7 \%(n=2)$, and structural malformations (a ventricular septal defect and an atrial septal defect) diagnosed among the remaining euploid cases $(n=10)$ with an NT of 3.0-3.4 mm were 
Table 3. Chromosomally abnormal fetuses

\begin{tabular}{|c|c|c|c|c|c|}
\hline & $\mathrm{CRL}(\mathrm{cm})$ & $\mathrm{NT}$ (mm) & Additional ultrasonography findings ${ }^{a}$ & Fetal death (gestational age) & $\begin{array}{l}\text { Pregnancy termination } \\
\text { (gestational age) }\end{array}$ \\
\hline \multicolumn{6}{|l|}{ Trisomy 21} \\
\hline 1 & 5.32 & 3.8 & & & Local \\
\hline 2 & 6.30 & 3.9 & & & Local \\
\hline 3 & 6.19 & 4.1 & Absent NB, TR, VSD & & Local \\
\hline 4 & 5.79 & 4.8 & & & Local \\
\hline 5 & 6.89 & 5.3 & & & Local \\
\hline 6 & 7.09 & 5.9 & Hydrops & 15 weeks 3 days & 15 weeks 3 days \\
\hline 7 & 7.84 & 6.2 & Absent NB, AVSD & 16 weeks & 16 weeks \\
\hline 8 & 5.01 & 6.6 & & & Local \\
\hline 9 & 5.72 & 7.6 & & & Local \\
\hline Median & 6.19 & 5.3 & & & \\
\hline \multicolumn{6}{|l|}{ Trisomy 18} \\
\hline 1 & 6.27 & 3.1 & VSD & & Local \\
\hline 2 & 4.73 & 3.7 & Hydrops & 15 weeks 2 days & 15 weeks 2 days \\
\hline 3 & 4.49 & 3.9 & & & 14 weeks 5 days \\
\hline 4 & 5.52 & 4.7 & & 13 weeks 3 days & 13 weeks 3 days \\
\hline 5 & 5.77 & 5.1 & & 13 weeks 3 days & 13 weeks 3 days \\
\hline 6 & 5.67 & 5.3 & & 16 weeks 1 days & 16 weeks 1 days \\
\hline 7 & 3.74 & 5.8 & & & Local \\
\hline 8 & 5.08 & 6.7 & & & Local \\
\hline 9 & 6.51 & 7.9 & Hydrops & & 16 weeks \\
\hline 10 & 6.72 & 7.9 & Hydrops & & 15 weeks \\
\hline 11 & 7.07 & 8.6 & & 17 weeks & 17 weeks \\
\hline 12 & 7.25 & 16.1 & AVSD & & 17 weeks 2 days \\
\hline Median & 5.72 & 5.5 & & & \\
\hline \multicolumn{6}{|l|}{ Trisomy 13} \\
\hline 1 & 4.49 & 4.8 & & 14 weeks & 14 weeks \\
\hline \multicolumn{6}{|l|}{ Monosomy X } \\
\hline 1 & 5.60 & 8.6 & Hydrops & & Local \\
\hline 2 & 8.99 & 10.2 & Hydrops, VSD & & Local \\
\hline Median & 7.30 & 9.4 & & & \\
\hline \multicolumn{6}{|c|}{ Partial monosomy and/or trisomy } \\
\hline 1 & 3.94 & 3.4 & Omphalocele & & 13 weeks 5 days \\
\hline 2 & 3.49 & 3.6 & Omphalocele & & Local \\
\hline 3 & 5.98 & 4.8 & VSD & & 16 weeks 1 days \\
\hline 4 & 6.06 & 5.3 & VSD, DORV & & 14 weeks 6 days \\
\hline 5 & 5.64 & 6.5 & & & 12 weeks 6 days \\
\hline Median & 5.64 & 4.8 & & & \\
\hline
\end{tabular}

${ }^{a}$ Additional ultrasonography findings in the first trimester or early second trimester.

CRL, crown-rump length; NT, nuchal translucency; NB, nasal bone; TR, tricuspid regurgitation; VSD, ventricular septal defect; AVSD, atrioventricular septal defect; DORV, double-outlet right ventricle.

found in one fetus. The prevalence of chromosomal defects has previously been reported to increase exponentially with NT thickness [14]. About 20\% of fetuses with increased NT thickness will have a chromosomal abnormality $[7,14]$. In the present study, 41.4\% of fetuses with increased NT thickness had a chromosomal abnormality, and the prevalence of chromosomal defects increased with NT thickness, as has been reported by others. In a previous study, in a chromosomally abnormal group, 
approximately $50 \%$ of cases had trisomy 21 , and $25 \%$ had trisomy 18 or 13 [6]. In the present study, approximately $40 \%$ had trisomy 18, and 30\% had trisomy 21 .

Several studies have shown that increased fetal NT thickness is associated with miscarriage or fetal death [15]. The prevalence of fetal death was 68 (5.2\%) in 1,320 euploid fetuses with an increased NT greater than $3.5 \mathrm{~mm}$; of these, 43 (63\%) died before 15 weeks of gestation [16]. The procedure-related risk of miscarriage is present in the 2 weeks post-CVS. In the present study, euploid fetal death occurred in two cases (2.9\%). In one case, in which miscarriage of a euploid fetus occurred within 6 weeks of CVS, fetal death was more likely related to the increased NT thickness $(3.6 \mathrm{~mm})$ or to another cause, rather than to the procedure. In the other case, CVS was performed at 11 weeks 6 days of gestation in a fetus with an NT of $10 \mathrm{~mm}$; this death was also more likely related to hydrops than to the procedure.

Several studies have reported that increased fetal NT thickness is associated with a high prevalence of genetic syndromes and major structural abnormalities, including major cardiac defects, diaphragmatic hernia, exomphalos, body stalk anomaly, skeletal defects $[4,6,8,15,17]$. However, there are large differences among existing studies in terms of the prevalence of major abnormalities, which reportedly ranges from 3-50\%, because of differences in the definition of an abnormal NT thickness $(2.5-5.0 \mathrm{~mm})$. In the present study, the prevalence of structural anomalies in chromosomally normal fetuses with increased NT thickness $(\geq 3.0 \mathrm{~mm})$ was $15.7 \%(\mathrm{n}=11)$, and 6 of these fetuses had a cardiac anomaly. A detailed, late first-trimester or secondtrimester ultrasonographic scan should be performed, with the aim of identifying structural anomalies, with a focus on the fetal heart.

Several studies have reported the prevalence of developmental delay with long-term follow-up of chromosomally and anatomically normal fetuses with a 1.12-7.14\% increased NT thickness [18-22]. Our study included a small number of cases and a short-term follow-up. In the present study, the prevalence of developmental delay in chromosomally and anatomically normal fetuses with increased NT thickness was $3.6 \%$. Additionally, $40 \%$ of fetuses with increased NT thickness resulted in the birth of a healthy infant with no major structural abnormality or developmental delay. Thus, it is not desirable to discourage parents solely on the basis of an increased fetal NT thickness.

In conclusion, a high prevalence of chromosomal defects with increased fetal NT thickness implies that it is necessary to perform prompt fetal karyotyping using CVS during the first trimester. Prompt karyotyping should reduce the parental stress associated with waiting. The overall rate of fetal loss following CVS is higher than that following amniocentesis. However, if background spontaneous losses are excluded, the procedure-related risk of miscarriage is actually lower. After the exclusion of chromosomal anomalies, detailed ultrasonographic examination, including fetal echocardiography at around 20 weeks of gestation, should be offered, to exclude major structural anomalies. We also suggest that if no chromosomal defect or structural anomaly is found, parents should be counseled that the likelihood of a good outcome is high.

\section{References}

1. Szabó J, Gellén J. Nuchal fluid accumulation in trisomy-21 detected by vaginosonography in first trimester. Lancet 1990;336:1133.

2. Nicolaides KH, Azar G, Byrne D, Mansur C, Marks K. Fetal nuchal translucency: ultrasound screening for chromosomal defects in first trimester of pregnancy. BMJ 1992;304:867-9.

3. Sheppard C, Platt LD. Nuchal translucency and first trimester risk assessment: a systematic review. Ultrasound 0 2007;23:107-16.

4. Bilardo CM, Pajkrt E, de Graaf I, Mol BW, Bleker OP. Outcome of fetuses with enlarged nuchal translucency and normal karyotype. Ultrasound Obstet Gynecol 1998;11:401-6.

5. Koos BJ. First-trimester screening: lessons from clinical trials and implementation. Curr Opin Obstet Gynecol 2006;18:152-5.

6. Souka AP, Von Kaisenberg CS, Hyett JA, Sonek JD, Nicolaides KH. Increased nuchal translucency with normal karyotype. Am J Obstet Gynecol 2005;192:1005-21.

7. Bakker M, Pajkrt E, Bilardo CM. Increased nuchal translucency with normal karyotype and anomaly scan: what next? Best Pract Res Clin Obstet Gynaecol 2014;28:355-66.

8. Maymon R, Weinraub Z, Herman A. Pregnancy outcome of euploid fetuses with increased nuchal translucency: how bad is the news? J Perinat Med 2005;33:191-8.

9. American College of Obstetricians and Gynecologists. ACOG Practice Bulletin No. 88, December 2007. Invasive prenatal testing for aneuploidy. Obstet Gynecol 2007;110:1459-67.

10. Haak MC, van Vugt JM. Pathophysiology of increased nuchal translucency: a review of the literature. Hum Reprod Update 2003;9:175-84.

11. Mol BW. Down's syndrome, cardiac anomalies, and nuchal translucency. BMJ 1999;318:70-1. 
12. Böhlandt $S$, von Kaisenberg CS, Wewetzer $K$, Christ $B$, Nicolaides $K H$, Brand-Saberi B. Hyaluronan in the nuchal skin of chromosomally abnormal fetuses. Hum Reprod 2000;15:1155-8.

13. Bekker MN, Haak MC, Rekoert-Hollander M, Twisk J, Van Vugt JM. Increased nuchal translucency and distended jugular lymphatic sacs on first-trimester ultrasound. Ultrasound Obstet Gynecol 2005;25:239-45.

14. Kagan KO, Avgidou K, Molina FS, Gajewska K, Nicolaides KH. Relation between increased fetal nuchal translucency thickness and chromosomal defects. Obstet Gynecol 2006;107:6-10.

15. Souka AP, Snijders RJ, Novakov A, Soares W, Nicolaides KH. Defects and syndromes in chromosomally normal fetuses with increased nuchal translucency thickness at 10-14 weeks of gestation. Ultrasound Obstet Gynecol 1998;11:391-400.

16. Souka AP, Krampl E, Bakalis S, Heath V, Nicolaides KH. Outcome of pregnancy in chromosomally normal fetuses with increased nuchal translucency in the first trimester. Ultrasound Obstet Gynecol 2001;18:9-17.

17. Bilardo CM, Müller MA, Pajkrt E, Clur SA, van Zalen MM, Bijlsma EK.
Increased nuchal translucency thickness and normal karyotype: time for parental reassurance. Ultrasound Obstet Gynecol 2007;30:11-8.

18. Adekunle O, Gopee A, el-Sayed M, Thilaganathan B. Increased first trimester nuchal translucency: pregnancy and infant outcomes after routine screening for Down's syndrome in an unselected antenatal population. Br J Radiol 1999;72:457-60.

19. Brady AF, Pandya PP, Yuksel B, Greenough A, Patton MA, Nicolaides $\mathrm{KH}$. Outcome of chromosomally normal livebirths with increased fetal nuchal translucency at 10-14 weeks' gestation. J Med Genet 1998;35:222-4.

20. Hiippala A, Eronen $M$, Taipale $P$, Salonen $R$, Hiilesmaa V. Fetal nuchal translucency and normal chromosomes: a long-term follow-up study. Ultrasound Obstet Gynecol 2001;18:18-22.

21. Senat MV, De Keersmaecker $B$, Audibert F, Montcharmont $G$, Frydman $R$, Ville $Y$. Pregnancy outcome in fetuses with increased nuchal translucency and normal karyotype. Prenat Diagn 2002;22:345-9.

22. Cheng CC, Bahado-Singh RO, Chen SC, Tsai MS. Pregnancy outcomes with increased nuchal translucency after routine Down syndrome screening. Int J Gynaecol Obstet 2004;84:5-9. 